\title{
A perspectiva dos alunos do ensino médio sobre educação ambiental e sustentabilidade na escola estadual serra das cordilheiras em Colméia-TO
}

\author{
High school students' perspective on environmental education and sustainability in serra das
} cordilheiras state school in Colméia-TO

Perspectiva de estudiantes de preparatoria sobre educación ambiental y sostenibilidad en la escuela estatal serra das cordilheiras en Colméia-TO

Recebido: 23/11/2021 | Revisado: 27/11/2021 | Aceito: 27/11/2021 | Publicado: 26/11/2021

\author{
Camila Mendonça Silva \\ ORCID: https://orcid.org/0000-0002-9977-0157 \\ Faculdade Guaraí, Brasil \\ E-mail: camila.meioambiente@ outlook.com \\ Patrícia Bispo Farias \\ ORCID: https://orcid.org/0000-0003-2604-3562 \\ Faculdade Guaraí, Brasil \\ E-mail: pbf_1607@outlook.com \\ Aluísio Vasconcelos de Carvalho \\ ORCID: https://orcid.org/0000-0002-3793-3133 \\ Faculdade Guaraí, Brasil \\ E-mail: aluisiovasconcelos@gmail.com
}

\begin{abstract}
Resumo
O presente trabalho busca identificar se a Escola Estadual Serra das Cordilheiras de Colméia - TO trabalha a temática educação ambiental e sustentabilidade de forma interdisciplinar buscando a formação de sujeitos ambientalmente críticos e sustentáveis, partindo da avaliação da percepção dos alunos do ensino médio por meio de uma abordagem qualitativa e uso do questionário. Os dados obtidos na coleta foram analisados e tabulados baseando-se em um enfoque quanti-qualitativo, com a participação de 123 alunos. Observou-se que 94,31\% ouviram falar sobre educação ambiental, no tocante aos professores trabalharem atividades relacionadas a educação ambiental em sala de aula $65,04 \%$ dos alunos responderam que apenas algumas vezes, revelando que a educação ambiental ainda não é uma temática trabalhada de forma interdisciplinar, embora a Política Nacional de Educação Ambiental (PNEA) imponha que o desenvolvimento destas atividades devem ocorrer de maneira transversal e interdisciplinar afim de tornar-se uma prática educativa integrada, contínua e permanente, em todos os níveis e modalidades do ensino formal, adequando-se as necessidades ambientais atuais, uma vez que se considera ser este um dos alicerces para buscarmos a tão sonhada sustentabilidade.
\end{abstract}

Palavras-chave: Educação ambiental; Interdisciplinaridade; Meio ambiente; Escola; Sustentabilidade; Ensino.

\begin{abstract}
The present work seeks to identify whether the Serra das Cordilleras de Colméia State School - TO works the theme of environmental education and sustainability in an interdisciplinary way, seeking the formation of environmentally critical and sustainable subjects, starting from the evaluation of the perception of high school students through a qualitative approach and use of the questionnaire. The data obtained in the collection were analyzed and tabulated based on a quantitative-qualitative approach, with the participation of 123 students. It was observed that $94.31 \%$ had heard about environmental education, with regard to teachers working activities related to environmental education in the classroom, $65.04 \%$ of students answered that only a few times, revealing that environmental education is not yet a topic worked in an interdisciplinary way, although the National Environmental Education Policy (PNEA) requires that the development of these activities must occur in a transversal and interdisciplinary manner in order to become an integrated, continuous and permanent educational practice, at all levels and modalities of teaching formal, adapting to current environmental needs, since this is considered to be one of the foundations for the long-awaited sustainability. Keywords: Environmental education; Interdisciplinarity; Environment; School; Sustainability; Teaching.
\end{abstract}

\section{Resumen}

El presente trabajo busca identificar si la Escuela Estatal Serra das Cordilleras de Colméia - TO trabaja el tema de la educación ambiental y la sustentabilidad de manera interdisciplinaria, buscando la formación de sujetos ambientalmente críticos y sustentables, a partir de la evaluación de la percepción del bachillerato. estudiantes a través de un enfoque cualitativo y uso del cuestionario. Los datos obtenidos en la colección fueron analizados y tabulados 
con base en un enfoque cuantitativo-cualitativo, con la participación de 123 estudiantes. Se observó que el 94,31\% había escuchado sobre educación ambiental, en cuanto a las actividades laborales de los docentes relacionadas con la educación ambiental en el aula, el 65,04\% de los estudiantes respondió que solo unas pocas veces, revelando que la educación ambiental aún no es un tema trabajado de manera interdisciplinaria. de manera, si bien la Política Nacional de Educación Ambiental (PNEA) exige que el desarrollo de estas actividades se dé de manera transversal e interdisciplinar para que se conviertan en una práctica educativa integrada, continua y permanente, en todos los niveles y modalidades de la enseñanza formal, adaptándose a necesidades medioambientales actuales, ya que se considera que es uno de los pilares de la tan esperada sostenibilidad.

Palabras clave: Educación ambiental; Interdisciplinariedad; Medio ambiente; Colegio; Sustentabilidad; Enseñanza.

\section{Introdução}

O dicionário da língua portuguesa define Educação como o ato ou efeito de educar (-se), processo pelo qual o ser humano irá desenvolver seus princípios, seu intelecto e aptidão física, bem como construir sua civilidade, por meio do educar e instruir (Ferreira, 2001). Deste modo, educação assemelha-se a uma via de mão dupla, onde ensinar e aprender trafegam rumo ao mesmo objetivo.

Semelhantemente, o conceito de Educação Ambiental (EA) segundo o PNEA (Política Nacional de Educação Ambiental) está pautado na compreensão de processos pelos quais o ser humano construirá não apenas valores sociais, mas conhecimentos, habilidades, atitudes e competências que o instruirão quanto a conservação do meio ambiente, tornando este um bem de uso comum a coletividade e essencial a melhoria da qualidade de vida, tal como sua sustentabilidade (ICMBIO, 2021).

A Constituição Federal em seu Artigo 225 diz que "todos têm direito ao meio ambiente ecologicamente equilibrado, bem de uso comum do povo e essencial à sadia qualidade de vida, impondo-se ao poder público e à coletividade o dever de defendê-lo e preservá-lo para as presentes e futuras gerações". Para assegurar a efetividade deste direito, incumbe ao poder público a promoção da educação ambiental em todos os níveis de ensino, integralizando a prática da lei de maneira multi, trans e interdisciplinar nos espaços escolares e não escolares (Brasil, 2021).

Para Luck (2003), a interdisciplinaridade engloba a integração e o envolvimento dos professores em um trabalho conjunto, promovendo a interação com as demais disciplinas escolares, com a finalidade de que estes possam estar ciente dos impactos que suas ações podem causar ao meio ambiente, exercendo assim criticamente a sua cidadania.

Reigota (2001), afirma que uma compreensão mais global, é o método que pode proporcionar intercâmbio de experiências entre professores e alunos e envolver toda comunidade escolar e extraescolar, possibilitando que as reflexões que os alunos adquiriram no ambiente escolar possam ser aplicadas em sua comunidade.

Logo, se olharmos para o ensino e a aprendizagem sob uma ótica interdisciplinar, compreenderemos que esta se destina ao aprofundamento dos conhecimentos partindo do ponto agregador das diversas áreas de conhecimento, considerando suas especificidades, criando um redimensionamento e expansão de sua função e percepção (Peixoto, 2016).

De maneira interdisciplinar, a educação ambiental se faz objetivando a construção de valores e práticas que perpassam uma conscientização ambiental, ela visa uma sensibilização que desenvolverá pensamentos de empatia no ambiente onde cada indivíduo está inserido. Desta forma, quando ocorre a junção da EA com a interdisciplinaridade, acredita-se que como resultado tem-se a solidificação de indivíduos não apenas ambientalmente críticos e sustentáveis, mais cidadãos capazes de refletir sobre a complexidade da sociedade em seu entorno, inalienados ao sistema político e econômico, sendo atores ativos no todo (Conrado \& Silva, 2017).

Reafirmando a sensibilização advinda de uma Educação Ambiental trabalhada de forma interdisciplinar, Jacobi (2003) ressalta que ao final deste processo as pessoas estarão mais qualificadas para gerar mudanças no tocante à degradação 
socioambiental, uma vez que estes agora são críticos, pensantes e agentes transformadores nos diferentes níveis de participação na defesa da qualidade de vida.

Ainda, o mesmo autor pontua que a Educação Ambiental está aquém da simples compreensão de conceitos ligados ao meio ambiente, a sustentabilidade, a prevenção e conservação, de sorte que esta se firma na construção de novos preceitos sociais, na obtenção de saberes, no posicionamento, nas maestrias e habilidades para a conquista e a manutenção do direito ao meio ambiente equilibrado.

Não obstante, embora a Educação Ambiental possua uma exigência legal, é necessário que esta seja trabalhada de forma dinâmica e prazerosa, pois enormes são os desafios para o seu desenvolvimento, requerendo atitudes concretas, que abranjam mudanças de comportamento no campo pessoal e comunitário, visando o bem comum. De sorte que, ao se propor verdadeiramente trabalhar a Educação Ambiental de forma interdisciplinar, é preciso entender que as dificuldades são grandes e precisam ser enfrentadas, pois, conforme Dias (1992), os problemas ambientais estão enraizados em fatores socioeconômicos, políticos e culturais e que estes não são previstos nem resolvidos por meios puramente tecnológicos, reforçando quão importante é a inserção da Educação Ambiental nas escolas, a fim de conscientizar estes alunos e ajudá-los a se tornarem cidadãos ecologicamente corretos, críticos e dotados de uma postura positiva frente aos desafios sociais.

Partindo do pressuposto, este trabalho tem por objetivo identificar se a escola trabalha educação ambiental de forma interdisciplinar por meio da percepção dos alunos investigados, e a partir do resultado mostrar de forma enfática a importância de realizar uma educação ambiental eficaz de forma interdisciplinar que forme cidadãos pensantes e críticos sobre o todo.

\section{Metodologia}

O presente trabalho foi desenvolvido no colégio Estadual Serra das Cordilheiras, que faz parte da rede pública estadual no município de Colméia-TO, durante o mês de setembro de 2021. Buscando investigar se a escola trabalha a EA e Sustentabilidade de forma interdisciplinar e se os alunos possuem uma postura crítica em relação aos princípios que norteiam o pensamento ecológico, foi decidido pelo uso de uma abordagem qualitativa, que segundo Minayo (2007) "são metodologias capazes de incorporar a questão do significado e da intencionalidade como inerentes aos atos, relações, estruturas sociais, uma vez que estas possuem uma compreensão nas construções humanas significativas" e quantitativa conforme Knechtel (2014) que afirma ser uma modalidade atuante sobre questões humano ou social.

Inicialmente, foi elaborado um questionário na plataforma da Microsoft Forms, composto por quinze perguntas, contemplando questões de múltipla escolha e questões abertas, referente ao tema supracitado. Em seguida, por intermédio da professora Campo, foi disponibilizado o link do questionário para os estudantes do $1^{\circ}, 2^{\circ}$ e $3^{\circ}$ ano do ensino médio na plataforma e grupos de WhatsApp que a escola usa para realizar suas aulas, alcançando um total de cento e vinte (120) estudantes participantes da pesquisa.

Após a coleta dos dados, foi realizada a tabulação dos resultados com o auxílio do software Excel, a fim de facilitar a montagem destes resultados e consequentemente a discussão por meio da estatística descritiva e abordagem fenomenológica conforme a metodologia adotada por Oliveira e Cunha (2008).

\section{Resultados e Discussões}

O questionário realizado com os alunos do ensino médio da escola estadual serra das cordilheiras no município de colmeia, TO. possibilitou avaliar a percepção dos alunos sobre educação ambiental e sustentabilidade que aponta para a importância de trabalhar EA de forma interdisciplinar na formação de sujeitos pensantes e críticos sobre o todo, teve participação de cento e vinte e três alunos, destes 59,35\% eram do sexo feminino e 40,65\% do sexo masculino, com idade entre 
14 e 18 anos, sendo que 27 alunos $(21,95 \%)$ estão no $1^{\circ}$ ano do ensino médio, 54 alunos $(43,90, \%)$ estão no $2^{\circ}$ ano e 42 alunos $(34,15 \%)$ no $3^{\circ}$ ano, conforme mostrado nas Tabelas 1 e 2.

Tabela 1. Distribuição da amostra por gêneros.

\begin{tabular}{|c|c|c|}
\hline \multicolumn{3}{|c|}{ Gênero } \\
\hline Feminino & 73 & $59,35 \%$ \\
\hline Masculino & 50 & $40,65 \%$ \\
\hline
\end{tabular}

Fonte: Autores.

Tabela 2. Distribuição da amostra por séries.

\begin{tabular}{|c|c|c|}
\hline \multicolumn{3}{|c|}{ Série } \\
\hline $\mathbf{1}^{\circ}$ Ano & 27 & $21,95 \%$ \\
\hline $2^{\circ}$ Ano & 54 & $43,90 \%$ \\
\hline $3^{\circ}$ Ano & 42 & $34,15 \%$ \\
\hline
\end{tabular}

Fonte: Autores.

Quando questionados se já tinham ouvido falar sobre educação ambiental, 94,31\% dos entrevistados responderam que sim e 5,69\% responderam que não. Observando o resultado acima, é revelado que a maioria dos alunos já ouviram falar sobre educação ambiental, porém não conseguiram definir o que é meio ambiente e desenvolvimento sustentável na pergunta aberta (oitava pergunta) do questionário, mostrando assim que a educação ambiental não é trabalhada como um item essencial na formação e educação, voltada para contribuir na resolução de problemas, na interdependência entre o meio ambiente e comunidade como um todo, objetivando o bem estar entre as comunidades (Leff, 2001).

Ao serem questionados sobre a definição de meio ambiente e desenvolvimento sustentável, a partir do que entendiam, fica evidente que a grande maioria não soube definir tal conceito, apresentando respostas "Florestas", "Desenvolvimento da natureza", "Meio ambiente é o conjunto de forças".

Diante destes resultados, percebe-se que muitos alunos ainda não conseguem definir sobre a temática meio ambiente e desenvolvimento sustentável, gerando assim uma reflexão de que ainda há muito o que fazer nas escolas. Segundo Lima (2004), a escola é um local privilegiado para se trabalhar a educação formal, estabelecer conexões e criar condições que possibilitem estimular os alunos a adotar concepções e posturas comprometidas com a sustentabilidade e com o desenvolvimento sustentável da sociedade onde ele está inserido.

Na pergunta referente aos professores trabalharem atividades relacionadas à educação ambiental em sala de aula, foi obtida respostas distintas para algumas conforme a Tabela 3, demonstrando o longo caminho a percorrer até que se alcance $100 \%$ de atividades relacionadas à EA trabalhadas pelos professores.

Tabela 3. Resposta para se os professores trabalham atividades relacionadas a educação ambiental em sala de aula.

\begin{tabular}{|c|c|c|}
\hline \multicolumn{3}{|c|}{ Os professores trabalham atividades relacionadas a educação ambiental em sala de aula? } \\
\hline Algumas vezes & 80 & $65,04 \%$ \\
\hline Sempre & 29 & $23,58 \%$ \\
\hline Raramente & 12 & $9,76 \%$ \\
\hline Nunca & 2 & $1,63 \%$ \\
\hline
\end{tabular}

Fonte: Autores. 
Ao vermos a Educação Ambiental sendo trabalhada de forma esporádica no espaço escolar percebe-se que a ausência de tais atividades depende sumariamente da vontade e disponibilidade do professor requerer em suas disciplinas. Nesse âmbito, o espaço escolar se mostra um ambiente aflorado para debater sobre as questões ambientais e a não integração interdisciplinar causa nos alunos dificuldades de compreensão dos conteúdos voltados ao meio ambiente e EA (Sato, 2002).

Leite et al., (2017) afirmam que a EA deve abranger todos os movimentos na unidade escolar, sendo abordada de forma interdisciplinar a fim de trabalhar as problemáticas ambientais com o intuito de que os alunos reflitam sobre qual mundo queremos e o que podemos fazer para melhorar tais aspectos.

Neste viés, foi questionado aos alunos sobre em qual disciplina a temática meio ambiente e sustentabilidade é trabalhada, disciplinas como: Biologia (89,43\%), Geografia $(74,80 \%)$ e Química $(21,14 \%)$ foram as mais citadas, seguidas por História $(5,69 \%)$ e Português $(1,63 \%)$, as demais disciplinas, incluindo matemática, não foram citadas em nenhuma das respostas, como mostra a Tabela 4 .

Tabela 4. Respostas sobre qual disciplina é trabalhada o tema meio ambiente e sustentabilidade.

\begin{tabular}{|c|c|c|}
\hline \multicolumn{2}{|c|}{ Em qual disciplina é trabalhada o tema meio ambiente e sustentabilidade? } \\
\hline Biologia & 110 & $89,43 \%$ \\
\hline História & 7 & $5,69 \%$ \\
\hline Português & 2 & $1,63 \%$ \\
\hline Geografia & 92 & $74,80 \%$ \\
\hline Química & 26 & $21,14 \%$ \\
\hline Matemática & 0 & $0,00 \%$ \\
\hline
\end{tabular}

Fonte: Autores.

Os resultados obtidos demonstram que, embora abordada em disciplinas além da biologia (e ciências), a educação ambiental ainda não é uma temática trabalhada de forma interdisciplinar, a Política Nacional de Educação Ambiental (PNEA) impõe que o desenvolvimento das atividades devem ocorrer de maneira transversal e interdisciplinar, não constituindo uma disciplina específica, mas tornando-se uma prática educativa integrada, contínua e permanente, em todos os níveis e modalidades do ensino formal (Alexandar \& Poyyamoli, 2014).

Borges e Oliveira (2011) afirmam que a educação ambiental por si só não é suficiente para solucionar as problemáticas ambientais, porém é de grande importância para sensibilizar e conscientizar os cidadãos no tocante a preservação ambiental.

Portanto, quando questionados se eles colocavam em prática os conhecimentos adquiridos nesta unidade escolar através das atividades ligadas à educação ambiental, 82,93\% responderam que sim, 15,45\% responderam que raramente e apenas $1,63 \%$ disseram que não, conforme mostra a Tabela 5.

Tabela 5. Resposta sobre colocar em prática os conhecimentos adquiridos na escola através das atividades ligadas à educação ambiental.

\begin{tabular}{|c|c|c|}
\hline \multicolumn{2}{|c|}{ Você coloca em prática os conhecimentos adquiridos nesta unidade escolar através das atividades ligadas a } \\
educação ambiental?
\end{tabular}

Fonte: Autores. 
Nesse sentido, questionou-se que atitude eles tomariam caso observasse um colega praticando uma ação de degradação ambiental, dando a eles quatro opções de resposta, distintamente 38,21\% responderam que "Além de pedir para evitar o que está fazendo, explicaria as consequências dos atos que estão sendo praticados", 37,40\% disseram que "Pediria para que a pessoa evitasse o que está fazendo", 21,95\% disseram que "Avisaria algum dos monitores ambientais ou a direção escolar", e apenas 2,44\% dos alunos responderam que "Ignoraria a situação", como demonstra a Tabela 6.

Tabela 6. Resultados obtidos da pergunta referente a qual atitudes tomariam diante de um aluno praticando degradação ambiental.

\begin{tabular}{|c|c|c|}
\hline \multicolumn{3}{|c|}{ Caso você observe um aluno praticando uma ação de degradação ambiental, qual atitude você tomaria? } \\
\hline $\begin{array}{l}\text { Além de pedir para evitar o que está fazendo, explicaria as consequências dos atos } \\
\text { que estão sendo praticados. }\end{array}$ & 47 & $38,21 \%$ \\
\hline Pediria para que a pessoa evitasse o que está fazendo. & 46 & $37,40 \%$ \\
\hline Avisaria algum dos monitores ambientais ou a direção escolar & 27 & $21,95 \%$ \\
\hline Ignoraria a situação & 3 & $2,44 \%$ \\
\hline
\end{tabular}

Fonte: Autores.

As respostas aqui obtidas (Tabela 5 e 6) corroboram o que Leff (2001) diz quanto ao indivíduo sensibilizado, aquele que foi tocado no "coração" e na "alma" percebendo-se parte integrado na trama da vida e na manutenção do equilíbrio da natureza, evidentemente que, ao passo que vão construindo saberes sobre e em Educação Ambiental, vão compreendendo seu papel no ambiente inserido e mudando a realidade a sua volta, constatando quão importante se faz o uso de uma EA interdisciplinar que almeja promover mudanças.

Os alunos também foram questionados sobre o que é ser uma pessoa sustentável, as respostas obtidas revelaram que, para 55,28\% dos alunos, ser uma pessoa sustentável é "Aproveitar o que o mundo nos oferece sem comprometer as vidas das futuras gerações", enquanto $44,72 \%$ disseram que ser sustentável é "não prejudicar o seu ambiente, mantendo suas coisas em ordem e visando um bom futuro para você mesmo".

Analisando estes resultados, demonstra que muito ainda há muito o que fazer na construção de pessoas sustentáveis, remetendo mais uma vez a importância da escola dentro da construção destas pessoas, haja vista que segundo Del Prette e Del Prette (2001), a escola possui um ambiente extremamente favorável para o ensino de condutas sociais de qualidade, entretanto é necessário que esta escola se reconheça como elemento vital no sentido de conscientização dos alunos, levando-os a compreensão de que nós, enquanto indivíduos, dispomos do direito a um meio ambiente saudável. Assim, se temos o direito, temos também a obrigação e o dever moral, ético e político de mantê-lo preservado não apenas para a atual geração, mas para as próximas também (Segura, 2001).

Ainda na pegada sobre meio ambiente e sustentabilidade, foi questionado aos alunos se eles achavam que a sacolinha plástica é a grande vilã da sustentabilidade. Para a resposta "Sim, porque depois de carregar as compras, elas viram, apenas sacos de lixo, que depois vão ser descartados de forma errada" foi obtido um total de 66,67\%, enquanto para a opção "Não, porque o problema não é a sacola em si, mas o uso que se faz dela e a forma como ela é produzida" teve-se 33,33\%.

Diante desse resultado, é perceptível que muitos alunos ainda não compreendem que o problema não é apenas a utilização da sacolinha plástica, bem como qualquer outro material que possa degradar o meio ambiente, mas sim a utilização desenfreada e a forma como é produzida, onde muitas vezes sua produção detém de produtos naturais não renováveis, consumo de energias e emissões de gases (Landim et al., 2016). 
Ainda sobre os autores, eles apontam para a importância de trabalhar a EA para que haja consciência na hora do consumo e descarte dos materiais, tendo em vista que para ocorrer a sustentabilidade, o consumidor também precisa repensar nas suas atitudes.

Dessa forma Brandalise et al., (2009), vão dizer que é necessário conscientizar toda a sociedade, para que ela entenda as consequências dos seus atos diante da preservação ambiental. Por conseguinte, Virgens (2011), afirma em seu estudo que a educação tem a capacidade de formar indivíduos com habilidade de refletir sobre os problemas ambientais.

Diante deste contexto, foi perguntado aos alunos qual tipo de problema ambiental era possível identificar em sua comunidade, foi dada a opção de marcarem mais de uma resposta, sendo que "Queimadas" obteve 84,55\%, seguida pelo "Lixo" com 82,93\%, "Poluição do Ar" com 56,10\%, "Desmatamento" com 55,28\% e por último "Poluição da Água" com 20,33\%, como mostra a Tabela 7 .

Tabela 7. Resultados sobre os problemas ambientais identificados na comunidade.

\begin{tabular}{|c|c|c|}
\hline \multicolumn{2}{|c|}{ Que tipo de problema ambiental você identifica na sua comunidade? } \\
\hline Queimadas & 104 & $84,55 \%$ \\
\hline Lixo & 102 & $82,93 \%$ \\
\hline Desmatamentos & 68 & $55,28 \%$ \\
\hline Poluição do ar & 69 & $56,10 \%$ \\
\hline Poluição da água & 25 & $20,33 \%$ \\
\hline
\end{tabular}

Fonte: Autores.

Notoriamente percebe-se que os alunos conseguem identificar os problemas ambientais presentes em sua comunidade, principalmente quando estes estão em maior evidência, como é o caso das queimadas, outro fator contribuinte para esse resultado é que o período de ocorrência da pesquisa coincide com o período de queimadas no município. Os alunos também apontaram o lixo como o segundo maior problema ambiental em sua comunidade, assemelhando-se aos resultados obtidos por Silva et al. (2016), em sua pesquisa sobre percepção ambiental no ensino médio, corroborando o que Dias (1992) afirma acerca do lixo ser um dos maiores problemas nas cidades brasileiras. Direta ou indiretamente, a escola está ligada a esse problema ambiental, não apenas por ser um local de grande produção desse lixo, mas pelo relevante papel que a instituição escolar tem na formação de cidadãos mais prudentes e cientes quanto seu papel ambiental.

Diante dessa realidade e partindo da abordagem sobre EA utilizando-se da interdisciplinaridade, a escola se torna um ambiente oportuno para trabalhar as mudanças, atitudes e comportamentos a fim de fazer com que os problemas ambientais sejam ao menos minimizados e futuramente solucionados totalmente, possibilitando assim que os recursos naturais para as próximas gerações não sejam prejudicados (Sato, 2004).

\section{Conclusões}

Diante dos resultados obtidos nesta pesquisa, conclui-se que o trabalhar da Educação ambiental sugerida por inúmeros autores e prevista em lei ainda não é uma realidade efetiva na escola e por parte dos professores, haja vista que apesar dos alunos mostrarem algum conhecimento acerca do meio ambiente e sustentabilidade, é visível que ainda estão presos somente àquele ensino raso, desenvolvido em datas comemorativas, como a semana do meio ambiente, dia da água, dentre outros.

Evidentemente que o pensamento crítico e o entendimento eficaz de educação ambiental e sustentabilidade ainda não é muito difundido entre eles, uma vez que um percentual relativamente grande de alunos não conseguem ter um posicionamento responsável e consciente frente aos assuntos ambientais, não conseguem formular conceitos básicos, como por 
exemplo o que foi solicitado no questionário e não conseguem visualizar os processos por trás das entrelinhas, as ações de cada indivíduo que ocasionou o produto final, as responsabilidades da sociedade frente às problemáticas ambientais.

Assim, faz-se necessário que o pensar e o executar de ações que almejam não apenas a preservação, a sensibilização e a conservação do meio ambiente, mas a própria formação de um sujeito ambientalmente crítico, pensante e atuante frente às grandes mudanças atuais, para isso a escola precisa se dispor a exercer seu papel formador e transformador através do processo de ensino-aprendizagem, buscando constantemente melhorar e refletir todo o contexto que está se desenrolando à sua frente, quebrando paradigmas e alguns obstáculos ainda presentes no ensinar, de forma que a EA por meio da interdisciplinaridade alcance de fato seu objetivo maior, uma vez que considera-se o caminho interdisciplinar o alicerce na busca e na construção de uma sociedade que viva a sustentabilidade por meio de suas ações.

À vista disso, espera-se que os resultados obtidos nesta pesquisa incentivem as escolas a trabalhar a EA de forma contínua e mais interdisciplinar focando na formação de cidadãos mais críticos perante o meio ambiente e a sustentabilidade. Quanto á trabalhos futuros é necessária uma investigação na formação dos professores para o ensino de EA, tendo em vista que uma formação profissional mais especifica na área abre portas para que aconteça a temática em salas de aulas.

\section{Referências}

Alexandar, R., \& Poyyamoli, G. (2014). A eficácia da educação ambiental para o desenvolvimento sustentável com base no ensino e aprendizagem ativos no ensino médio - um estudo de caso nas regiões de Puducherry e Cuddalore, na Índia. Jornal da educação para a sustentabilidade, 7 (1), 1-20.

Borges, E. A., \& Oliveira, M. A. D. (2011). Educação ambiental com ênfase no consumo consciente e o descarte de resíduos-uma experiência da educação formal. Anais... II SEAT-Simpósio de Educação Ambiental e Transdisciplinaridade UFG/IESA/NUPEAT-Goiânia.

Brandalise, L. T., Bertolini, G. R. F., Rojo, C. A., Lezana, Á. G. R., \& Possamai, O. (2009). A percepção e o comportamento ambiental dos universitários em relação ao grau de educação ambiental. Gestão \& Produção, 16, 273-285.

Conrado, L. M. N., \& da Silva, V. H. (2017). Educação ambiental e interdisciplinaridade: um diálogo conceitual. Revista Gestão \& Sustentabilidade Ambiental, 6(3), 651-665.

Constituição República Federativa do Brasil de 1988. (1998).

de Oliveira, G. S., \& de Oliveira Cunha, A. M. (2021). Breves considerações a respeito da fenomenologia e do método fenomenológico. Cadernos da FUCAMP, 20(47).

Del Prette, A., \& Del Prette, Z. A. P. (2001). Psicologia das relações interpessoais: Vivênciaspara o trabalho em grupo. ed. -Vozes.

Dias, G. F. (1992). Educação Ambiental: princípios e práticas. Gaia. 224p.

Ferreira, A.B. H. (2001). Mini Aurélio século XXI escolar: O minidicionário da língua portuguesa. (4a ed.), Ver. Ampliada.

ICMBIO. Educação Ambiental. PNEA. 〈https://www.icmbio.gov.br/educacaoambiental/politicas/pnea.html〉.

Jacobi, P. (2003). Educação ambiental, cidadania e sustentabilidade. Cadernos de pesquisa, 189-206.

Knechtel, M. R. (2014) Metodologia da pesquisa em educação: uma abordagem teórico-prática dialogada. Intersaberes.

Landim, A. P. M., Bernardo, C. O., Martins, I. B. A., Francisco, M. R., Santos, M. B., \& Melo, N. R. D. (2016). Sustentabilidade quanto às embalagens de alimentos no Brasil. Polímeros, 26, 82-92.

Leff, E. (2001). Epistemologia ambiental. Cortez.

Leite, I. A., Leite, C. A., \& Leite, C. A. (2017). Percepção de alunos acerca de educação ambiental em uma comunidade escolar, PatosPB. Biodiversidade, 16(2).

Lima, W. (2004). Fórum Crítico da Educação. Revista do Instituto Superior de Estudos Pedagógicos, 3(1).

Lück, H. (2003). Pedagogia interdisciplinar: fundamentos teórico-metodológicos. (11a ed.), Vozes.

Minayo, M. C. S. (2007). Trabalho de Campo: Contexto de Observação, Interação e Descoberta. In: MINAYO, M.C.S (Org.). Pesquisa Social: teoria, método e criatividade. Editora Vozes.

Peixoto, E. S. A (2016) Interdisciplinaridade no Ensino Médio Integral. Disponível em: <https://educacaopublica.cecierj.edu.br/artigos/16/17/ainterdisciplinaridade-no-ensino-mdio-integral> Acesso em 3 set. 2021.

Reigota, M. (2001). O que é educação ambiental. Brasiliense.63p. 
Research, Society and Development, v. 10, n. 15, e569101523781, 2021

(CC BY 4.0) | ISSN 2525-3409 | DOI: http://dx.doi.org/10.33448/rsd-v10i15.23781

Sato, M. (2004). Educação Ambiental. RiMa.

Segura, D. S. B. (2001). Educação Ambiental na escola pública: da curiosidade ingênua à consciência crítica. Annablume: Fapesp. 214p.

Silva, M. S., Silva, E. T. M., Júnior, A. C. S., Silva, D. M., Azeredo, G. A. (2016). Percepção ambiental no ensino em escola pública de Solânea - PE. I Congresso Internacional das Ciências Agrárias COINTER - PDVAagro.

Virgens, R. A. (2001). A educação ambiental no ambiente escolar. xi, 17 f., il. Monografia (Licenciatura em Ciências Biológicas) - Consórcio Setentrional de Educação a Distância, Universidade de Brasília, Universidade Estadual de Goiás, Brasília, 2011. 